\title{
Las ciencias sociales ante el desafío de la integración social intercultural entre todos los pueblos de la tierra: Fenomenología, Hermenéutica y Praxeología
}

\author{
Iván Canales Valenzuela \\ Universidad Santo Tomás, Sede Talca, Chile \\ Email: canalesvalenzuela61@gmail.com
}

\begin{abstract}
Resumen: Este articulo tiene por finalidad reflexionar, críticamente, sobre la epistemología de las ciencias sociales hoy, y en su potencial categorial para pensar sistemáticamente una integración social intercultural, radicalmente plural, y socio-éticamente sustentable, es decir, en condiciones de un dialogo global, participativo en libertad y justicia.

Palabras clave: integración social, perspectiva hermeneútica, fenomenológica, praxeológica.
\end{abstract}

\section{Social sciencesin the face of the challenge of social} intercultural integration among all peoples of the earth: Phenomenology, Hermeneutics andPraxeology

Abstract: This article aims to think critically on the epistemology of social sciences today, and their categorical potential to systematically think asocial intercultural integration radically plural and socio-ethically sustainable, that is, in conditions of a participative global dialogue in freedom and justice. praxeological.

Keywords: social integration, prospects hermeneutics, phenomenology,

\section{As ciências sociaise os desafiosdaintegração socialinterculturalentre todos ospovos da terra: Fenomenologia, Hermenêutica ePraxeologia}

Resumo: Esteartigo tem como objetivorefletir criticamente sobrea epistemologiadas ciências sociaishoje, eno seu potencialcategórial para pensarsistematicamenteumaintegração socialintercultural,radicalmenteplurale sócioeticamente sustentável, ou seja, capaz deestabelecer um diálogo global, participativo em liberdade e justiça.

Palavras-chave: Integração social, perspectiva hermenêutica, fenomenológica, praxeológica. 


\section{Introducción}

En América Latina y el mundo, el encuentro entre pluralidad de culturas, hoy es un hecho irrefutable. Las problemáticas que dicho encuentro suscita,cuestionan de raíz los presupuestos éticos y políticos que sustentan a las democracias liberales occidentales (Estados nacionales vs. postnacionales; pluralidad vs. pluralismo y tolerancia; etc. $)^{1}$, y a las bases epistemológicas de las ciencias sociales, que normalmente conciben el vínculo social desde presupuestos socio-antropológicos inherentes a una sola tradición cultural o sólo al mundo de la vida europeo-occidental. Ahora bien, lo que aquí está en juego es la posibilidad de fundar racionalmente un marco conceptual para pensar teóricamente las condiciones y posibilidades de construcción de dicho espacio socio-ético, que tenga como imperativo categórico fundamental, a la Integración Social de Todos los Pueblos de la Tierra.

Con el objeto de poder colaborar a esta reflexión sobre una epistemología de las ciencias sociales, que dé cuenta del ingente desafío de pensar una integración social intercultural de carácter global, queremos exponer y desarrollar fenomenológicamente la Idea de una Integración Social Intercultural entre Todos los Pueblos de la Tierra. Idea que operará en dos niveles, a saber, primero como esencia intencional que define el objeto de las ciencias sociales y, segundo, como imperativo categórico que postule a la inclusión de todos los pueblos y de todas las culturas del planeta como interlocutores legítimos en la tarea de pensar y desarrollar los desafíos sociales, políticos y económicos de la integración social deseada. Para lograr este objetivo en 1 (perspectiva hermenéutica) desarrollaremos un breve diagnóstico de las exclusiones epistemológicas inherentes a las ciencias sociales en su concepción del vínculo social, pues cuando el vínculo social se define desde la raza, la nación, la cultura, o desde la categoría de mundo de la vida (Lebenswelt) compartido, epistemológicamente, se hace imposible pensar el vínculo social entre pluralidad de culturas, etnos y naciones. En 2 (perspectiva fenomenológica) realizaremos una descripción fenomenológica de la Idea de Integración Social Intercultural entre Todos los Pueblos de la Tierra, con el fin de ofrecer una comprensión del vínculo social, que en su génesis y estructura sea radicalmente plural. Debido a la brevedad del espacio disponible, quedará pendiente el desarrollo de 3 (perspectiva praxeológica), es decir, el diseño de metodologías praxeológicas para la una intervención social eficaz, en función de la integración social deseada, a saber, radicalmente inclusiva donde todos los pueblos de la Tierra sean legítimos interlocutores en condiciones de libertad y justicia y de sustentabilidad medioambiental.

\section{Perspectiva hermenéutica: Diagnóstico sobre las exclusio- nes epistemológicas inherentes a las ciencias sociales en su concepción del vínculo social}

Efectivamente, desde los años 90 asistimos a una progresiva intensificación de la mundialización de los vínculos sociales o de la vida 
social, sin embargo, la teoría social clásica, ha quedado aprisionada en concepciones epistemológicas del vínculo social, pre-globalizadoras, sujetas, en lo principal, al concepto normativo de modernización, desarrollo y progreso. La efectiva globalización de los intercambios económicos a través de las informática, las telecomunicaciones ha favorecido, de hecho, el transito mercantil de divisas, bienes, servicios y de personas, acortando o aboliendo los espacios y las distancias existente entre todos los pueblos de la Tierra. El fenómeno migratorio es dramáticamente global y en una sola dirección, desde los países pobres hacia los más ricos. Por otro, lado los medios de comunicación de masas, controlan la información mundial a través de cuatro o cinco cadenas de noticias, y socializan un modo de vida único, a saber, el de las sociedades de mercado, que impone el imperio neoliberal reinante. Grandes corporaciones transnacionales hoy controlan la economía, la política, las comunicaciones, los saberes y las comunicaciones globales.

Sin embargo, se nos intenta ocultar que las estrategias de exclusión social inherentes a la economía, a la política, y a las sociedades de mercado hoy imperantes, también se globalizan. Y se globalizan también, los impactos medioambientales de una economía global movida por la codicia de los grandes capitales transnacionales, que en lo fundamental depreda los recursos naturales del planeta, bajo la ideología de un crecimiento económico sostenido que tiende hacia el infinito. Por otro lado, los estados nacionales tienden a convertirse en correas de transmisión de la economía mundial a la economía interna, generando con ello grandes dinámicas de desigualdad social y de exclusión social siempre crecientes.

Desde este apretado diagnóstico podemos vislumbrar desde ya, los desafíos que deben enfrentar las actuales ciencias sociales ante el desafío de la integración social, en un contexto de máxima, creciente e inorgánica globalización: de la economía, de la política, de los vínculos sociales, de las crisis medioambientales, etc. Complejiza este contexto, el hecho, de que lo que se globaliza afecta a una ingente pluralidad de pueblos con distintas identidades culturales y cosmovisiones de mundo. Integración social global, en contextos de radical pluralidad cultural, ese es el problema ${ }^{2}$.

Ante este nuevo escenario, las ciencias sociales tienen, por una parte, el ingente desafío de pensar sistemáticamente, la integración social, éticamente exigible. Y, por otra, la urgencia de revisar el propio aparato epistemológico categorial, para que la integración social deseada emerja sistemática y orgánicamente de un aparato conceptual sólido, que efectivamente, apunte a cambiar, de raíz, todo aquello que genera sistémicamente, exclusión social, y no quedarse en declaraciones de buenas intenciones respecto de la integración social deseada, pero con aparatos epistemológicos categoriales, que son en su esencia excluyentes de la integración social que se pretende construir. Precisamente porque conciben el vínculo social, desde premisas, socio-antropológicas eurocéntricas y discriminadoras de otras orgánicas sociales posibles, que desde el eurocentrismo epistemológico son calificada como de primitivas, preconvencionales, convencionales, 
premodernas, etc. De hecho, incluso las reivindicaciones que hoy se hace (desde el eurocentrismo epistemológico y socio-ético imperante), de los Pueblos Originarios, tienen una concepción marcadamente, museográfica de los mismos.

Observemos ahora brevemente, cómo la teoría social moderna y contemporánea ha concebido el vínculo social y las aporías que dichas concepciones nos plantean.

Max Weber en su sociología comprensiva ${ }^{3}$ parte de la tesis de que el objeto de estudio de la disciplina es la acción social. Sin embargo, define primero lo que es una acción humana y posteriormente, establece qué es lo que le otorgaría su carácter de social. Por ello, sostiene que la acción se distingue del mero comportamiento, en la medida en que el actor o los actores unen a él un sentido subjetivo. Pero no cualquiera acción con sentido es acción social. La acción social para Weber son aquellas acciones con sentido que norman el comportamiento de los otros, norman las relaciones intersubjetivas. Por tanto, no todo contacto entre personas es propiamente acción social. Es necesario que el sentido del propio comportamiento incluya a los otros. Por eso determinados comportamientos meramente reactivos, aunque estén provocados por otros, no son propiamente sociales, pues no incluyen un sentido.

Los distintos tipos de sentido que pueden estar unidos por el sujeto a la acción, determinan según Weber, distintos tipos de acción social. Weber distingue entre acciones racionales respecto a fines, racionales respecto a valores, acciones afectivas y acciones tradicionales. Sin embargo, las acciones propiamente sociales, en sentido estricto, serían las racionales. Y a la sociología que quiera ser comprensiva le interesan las acciones racionales con sentido. Pues comprender significa captar el sentido mentado en un caso individual, el sentido promedio en consideraciones grupales, o el sentido construido según tipos ideales. Con este modelo de acción se consiguen reglas prácticas que permiten comprender las acciones reales como desviaciones respecto a los tipos ideales.

Para Weber, una relación social consiste en un comportamiento recíprocamente orientado según un sentido. No consiste en solidaridad ni en su contrario. Se trata simplemente de la posibilidad de que tenga lugar un comportamiento recíproco previsible según un determinado sentido. Por tanto, para Weber no hay relación social sin sentido mentado por un actor. Para que en mis relaciones sociales estén incluidos los otros es necesario que el sentido de mis acciones esté referido a ellos. Y esto significa que no hay relaciones sociales sin una mínima comunidad de sentidos accesibles a todos los actores. Es decir, sin un mundo de la vida (Lebenswelt) común. De aquí que sea difícil, desde la teoría de Weber, comprender los vínculos sociales mundiales, como verdaderas acciones sociales.

Muchos de estos vínculos, por ejemplo de carácter económico o ecológico, no tienen por qué ser conscientes para los actores sociales. 
Incluso tratándose de vínculos reales y conscientes, no siempre me es accesible el sentido que los actores dan a sus acciones. Por ejemplo, en el caso de los daños ecológicos, la realidad de los mismos puede escapar tanto a la conciencia de todos los actores (los causantes y los que sufren los efectos de los mismos), pero esto no niega la existencia de vínculos sociales reales. Ciertamente, Weber no negaría la realidad de tales vínculos, pero no los consideraría como el objeto específico de una sociología comprensiva. O de otro modo, la sociología comprensiva parece no ser el marco categorial adecuado para pensar sistemáticamente la realidad de la sociedad mundial emergente.

Problemas análogos encontramos en el interaccionismo simbólico de George H. Mead ${ }^{4}$, quien desde su peculiar conductismo social, postula que: la hominización consiste en el paso de meros gestos dotados de un significado estimúlico inconsciente a la significación lingüística consciente. $\mathrm{Y}$ eso es algo que acontece, no en la subjetividad de un actor dado, sino en la vida social. En ella cristalizan las significaciones, forjándose símbolos dotados de universalidad. Ahí es también donde las posibles actitudes particulares de los otros toman forma en una actitud o punto de vista que Mead denomina, el otro generalizado. Y ahí es finalmente donde los objetos físicos se convierten en objetos sociales, cuyas reacciones podemos también prever. La conciencia no es, por tanto, algo que está dentro del cerebro, sino un carácter del proceso social humano. El espíritu humano no es otra cosa que la capacidad de retener las distintas posibilidades de reacción del otro generalizado ante los símbolos. Por ello el espíritu humano no es una realidad sustancial anterior al proceso social sino que se constituye en la matriz empírica de las interacciones sociales, simbólicamente mediadas.

En la perspectiva de nuestro análisis, de pensar sistemáticamente una sociedad mundial, la propuesta de Mead, presenta la dificultad de que ésta, supondría la existencia de símbolos universalmente compartidos que posibilitaran el que las significaciones sociales estuvieran reflejadas en la conciencia de cada uno de los habitantes del planeta. En cierto modo, nos encontramos en la misma situación en la que nos había dejado Max Weber. Aunque Mead ha superado su perspectiva subjetivista, mostrando que la persona surge de la interacción social, no ha superado la idea de la sociedad como una comunidad consciente de sentido. La interacción lingüísticamente mediada es una interacción consciente, que requiere símbolos (y, por tanto sentidos) comunes. Y éstos no se dan necesariamente en la sociedad mundial. Mead ha quedado preso del paradigma moderno de la conciencia, por mucho que señale que esta conciencia se construye socialmente.

Similares dificultades encontramos en la sociología funcional sistémica. Para Emile Durkheim ${ }^{5}$, por ejemplo, la evolución de las sociedades humanas está en buena medida determinada por el progreso en la división social del trabajo social. Este es el hecho positivo que la sociología ha de conceptuar. Sin embargo, la constitución de la sociedad no es un fenómeno laboral, sino moral, que tiene su expresión visible en el derecho. Esta 
unidad moral presupone la participación en unas mismas formas de pensar, sentir y obrar. Por ello, lo que garantiza la unidad moral de una sociedad es la participación en una misma conciencia colectiva. La condición, naturalmente, es que la división del trabajo vaya produciendo al mismo tiempo un derecho y una moral. De hecho los conceptos de Durkheim se limitan al estudio y análisis de estados nacionales específicos, pues sólo de ellos se puede hablar de una de una conciencia colectiva que se expresa en una verdadera unidad jurídica. En cambio, una sociedad mundial, intelectual y moralmente plural, esto no parece posible, precisamente, porque se ha puesto el vínculo social en el ámbito de la conciencia colectiva.

Con Talcott Parsons ${ }^{6}$, el sistema cultural es el encargado de mantener la integración funcional de todo el sistema. Pues, es la integración de pautas, de valores comunes con la estructura de la personalidad, la que constituye el fenómeno central de la dinámica de los sistemas sociales. La cultura no es solamente transmitida y aprendida, sino que la cultura es compartida.

Parsons piensa que, para que haya verdadera integración social, se requiere que todos los actores sociales compartan unas mismas pautas culturales. Por eso mismo, Parsons nunca pudo admitir la realidad de un sistema social mundial.

N. Luhmann ${ }^{7}$ postula una funcionalización sistémica del concepto de sentido, donde los sistemas de sentido son anteriores al sujeto. Pero, se mantiene una anterioridad explicita del sentido sobre la acción. Lo que remite necesariamente a la configuración de lo social como los sistemas de sentidos a un solo mundo de la vida (Lebenswelt) que comparte un mismo y único horizonte socio-cultural. Por ende, se excluye también la posibilidad de pensar desde Luhmann una integración social de carácter global, pues la sociedad mundial, sólo podría configurarse desde los sistemas de sentido de la sociedad imperial que resulte vencedora.

La teoría de los sistemas mundiales de I. Wallerstein ${ }^{8}$, también operara con un concepto deficiente de sociedad que les impide hablar de una sociedad mundial, pues se sigue pensando la sociedad en términos de integración en una interacción simbólicamente mediada, en una conciencia colectiva o en una cultura.

En la sociología primera de la acción comunicativa de Habermas ${ }^{9}$, se establecen las problemáticas relaciones entre mundo de la vida y sistema, donde es la racionalidad comunicativa que emerge del mundo de la vida (Lebenswelt) la que debe proveer de las categoría racionales necesarias para la configuración de una integración social dialógica, donde todos son legítimos interlocutores. Sin embargo, la integración social señalada sólo es posible para sociedades post-convencionales, pues, sólo de su mundo de la vida pueden emerger las categorías racionales reflexivas, que posibilitan en diálogo social comunicativo. Una integración social de carácter global con pluralidad de mundos de vida en concurrencia, epistemológicamente, 
desde la dialógica comunicativa, no es posible, pues las post-convencionales son sólo las sociedades desarrolladas del primer mundo.

Como sea, en este breve y apretado periplo por la teoría social contemporánea, nos encontramos con una concepción del vínculo social que presupone la configuración de lo social como sistemas de sentidos, sistemas de símbolos, creencias y tradiciones comunes etc. Y no puede concebir lo social como un sistema de pluralidad cultural radicalmente heterogénea. Es decir, no hay categoría para pensar la integración social de lo radicalmente plural, como lo es la sociedad mundial. Toda la hermenéutica social contemporánea, epistemológicamente, deja entrever que una sociedad mundial sólo puede implicar la integración social a los sistemas de sentidos que impongan los vencedores. Y el sistema económico global, capitalista y neoliberal, de hecho va en esta dirección. Por tanto, pensar una integración social intercultural de carácter global, reviste un ingente desafío teórico y reflexivo de máxima urgencia, donde todos deben ser concebidos como legítimos interlocutores. Por ello nuestro próximo apartado, pretende esbozar una concepción sistemática de lo social, que intenta superar las aporías señaladas.

\section{Perspectiva fenomenológica: Sobre la Idea de Integración Social Intercultural entre Todos los Pueblos de la Tierra}

Nuestra perspectiva fenomenológica nos obliga a preguntarnos por la esencia intencional, dequé es lo social, cómo surge, cómo se configura. Es evidente que sobre este tópico, lo que necesitamos es levantar o construir una IDEA muy bien fundada sobre el ser de lo social y las nociones que lo configuran.Para luego, desde una perspectiva hermenéutica mostrar sus diversas configuraciones socio-históricas. Luego, será en el cruce sistemático entre fenomenología y hermenéutica, que podremos esbozar una propuesta de praxis social socio-éticamente configurada que sea integradora de lo radicalmente plural y heterogéneo. Se trata por tanto, de pensar sistemática y orgánicamente al sistema de nuestras interacciones sociales posibles. Postulamos la Idea de sistema, porque es la que mejor articula lo radicalmente plural como una unidad orgánica. O de otro modo, es la Idea de sistema la que nos permite pensar, una sociedad mundial, su pluralidad y la coordinación e integración social que le es debida. Es decir, desde una bien fundada fenomenología del sistema de nuestras interacciones sociales, podremos articular hermenéuticamente a la pluralidad de pueblos que configuran al Todo Social mundial.

Lo primero en nuestro periplo epistemológico es postular que el ser humano es una realidad eminentemente social, todas sus codificaciones socioculturales con las que se desplaza en el mundo son productos sociales, a saber, realidad, lenguaje, conciencia, naturaleza, cultura. Incluimos la naturaleza, porque sea lo que sea ésta, el ser humano se relaciona siempre con su comprensión particular de la naturaleza, pero nunca con la naturale- 
za en sí. Lo importante aquí es visualizar el hecho inconcuso de que el ser humano para estar en el mundo no tiene algoritmos biológicos cerrados o instintos que le permitan resolver las relaciones con la naturaleza, con los otros hombres, las relaciones consigo mismo y los modos de sobrevivir y reproducir la especie. Todo ello el hombre, en todo tiempo y lugar, lo resuelve a base de códigos elaborados y legitimados socialmente. O de otro modo, el despliegue del ser humano en el mundo no es natural, todas sus dimensiones son esencialmente sociales incluso el cuidado de su salud corporal. Por tanto, en el ser humano lo social y su sociabilidad es un dato ontogenético y no una dimensión más de lo humano frente a lo individual. Lo individual siempre emerge dentro de un contexto de sociabilidad posible y, por tanto, está siempre subordinado a dicha sociabilidad. O de otro modo, lo individual es siempre un producto social. Por tanto, los social emerge siempre allí donde hay más de un individuo sobre la Tierra. De hecho, si un ser humano está vivo es porque está con otros seres humanos compartiendo alguna orgánica social posible, por elemental que esta sea. Luego el ser humano es ontogenéticamente social antes de cualquier modo de sociabilidad posible (clanes, tribus, etnias, naciones, culturas, etc.). El ser humano para estar vivo requiere de la presencia de los otros en la tensión dinámica de las pulsiones de competitividad (para los procesos de individuación) y de cooperación (para los procesos de construcción de estructuras sociales). Por tanto, es inherente a la condición humana el construir estructuras sociales posibles. Pues es el único modo que tiene el ser humano, de estar vivo y de producir y reproducir la especie. Por tanto, toda compresión de lo social desde sistemas de sentidos, tradiciones, símbolos y valores compartidos, llega muy tarde a la comprensión de lo social. Y tiende, como sucede de hecho, con la teoría social contemporánea a legitimar epistemológicamente la exclusión de lo plural y radicalmente otro.

Lo que hoy las ciencias sociales, tienden permanentemente a confundir es la IDEA de condición social del ser humano con las diversas formas de estructuras y orgánicas sociales posibles. Estás formas son socio-históricas, se configuran dinámicamente en el tiempo, por tanto son también provisionales, es decir, son socioculturales. Y por milenarias que puedan ser esta formas sociales y culturales, nunca podrán constituir ontogenia, sólo construyen modos de sociabilidad posibles. Efectivamente, toda sociedad y cultura o sistema de sentido particular, sólo es un modo de configuración funcional de una condición humanaque es universal, a saber, su intrínseca sociabilidad. Por tanto, nunca debiera ser problemático el pensar la emergencia y convivencia entre pluralidad de formas de sociabilidad posibles y tampoco debiera ser problemático el pensar la coordinación social, global de todas ellas. No hay nada en la ontología de lo humano que ponga límites a priori a alguna de estas alternativas. Por tanto, la misma Idea de lo social, presupone y postula la pluralidad de formas de sociabilidad posibles como radicalmente legítimas y la posible coordinación social entre todas ellas también. Porque el vínculo social entre seres humanos, nunca puede estar fundado en el etnos, o en tradiciones y sistemas de valores y de sentidos compartidos, sino que siempre debe estar fundado ontogenéticamente en la propia condición humana la cual no pue- 
de existir en el mundo sin en vínculo social ontogenético. Lo plural y radicalmente otro es siempre anterior a todo vínculo que esté modulado por alguna forma de organización social específica. Ahora bien, en la misma Idea de sociabilidad posible está anclada la noción a priori de coordinación de la acción social, la cual empíricamente puede ser realizada de dos modos alternativos y excluyentes entre sí, o a través del diálogo respetuoso entre todos los interlocutores o a través de la brutalidad armada. Son los seres humanos de modo absolutamente autónomo, quienes escogen de qué modo van a coordinar la acción social. Sin embargo, le repugna a la razón que dicha coordinación no sea a través del logos y que no tienda hacia la paz perpetua entre todos los pueblos de la Tierra. También, de modo a priori, la Idea de lo social presupone la noción de Todo Social y su Bien-Estar, es decir, satisfacer las condiciones de producción y reproducción de la especie para todo el grupo social, posibilitando la vida (y la vida buena) y la derrota de la muerte.Luego de modo a posteriori, a partir de la experiencia de personas socialmente excluidas, emerge el concepto de integración social. Para las ciencias sociales es un concepto normativo el imperativo de la integración social de todas las personas y grupos que configuran al Todo Social.Por ello, también a posteriori y de modo concomitante, emerge el concepto de emancipación, en la medida en que las dinámicas de lo social excluyen, marginan y oprimen. Así es, la sola Idea fenomenológica de lo social, poseeya, todo este rendimiento crítico y socio-ético que le es esencial.

Fenomenológicamente, es evidente que, aunque la coordinación de las acción social, a través de la violencia, es una posibilidad para todo grupo social, dicha alternativa, le repugna a una razón éticamente configurada. Por tanto, es razonable postular que la coordinación de la acción social debe siempre ser a través del logos. Y concebir el uso de la violencia como una anomalía o una excepción de aquello que es debido. Ahora bien, coordinar la acción social a través del logos, presupone de hecho, que esta coordinación debe configurarse a través de un diseño inteligente, pues nada hay en la naturaleza de la condición humana, que pueda orientar o normar esta alternativa. Para nosotros como occidentales, el modelo paradigmático de uso del logos (razón y discurso público) como coordinación de la acción, es el diseño de la polis (dialogo participativo y simétrico entre libres e iguales). Por tanto, la constitución de un sistema de nuestras interacciones sociales a nivel global, dicha unidad sistémica, sólo podemos pensarla como diseño inteligente desde el horizonte de la polis. $\mathrm{O}$, de otro modo, se trata de construir una unidad cosmopolita, que coordina y norma la integración social de lo radicalmente plural, como un diálogo sin exclusiones (todos son legítimos interlocutores) y en condiciones de libertad y justicia.

Desde estas consideraciones, concluimos que toda hermenéutica social contemporánea sólo puede realizarse sistemáticamente desde los meta-conceptos o Ideas normativas de sociedad (como sistema global de nuestras interacciones sociales) y polis (como diseño inteligente para la coordinación y la integración social). Es evidente también que todo proce- 
so económico y de construcción de división social del trabajo, deben estar subordinados a estos meta-conceptos. Pero también este esbozo fenomenológico de la esencia intencional de lo social, efectivamente, debe ser normativo para toda ciencia social posible. Y, también, para el propio concepto de Estados Nacionales, los cuales conciben, hoy, su identidad social y política como diferenciación y negación de la identidad de los Otros. Cabe subrayar por último, que desde esta fenomenología normativa las identidades socioculturales deben ser radicalmente respetadas en sus diferencia, originalidad y alteridad, pero también deben poder negociarse cotidianamente en la interacciones con los otros. O de otro modo, las identidades socioculturales concebidas museográficamente constituyen un atentado socio-ético en contra del dinamismo inherente a toda configuración de identidad social y cultural posible. Identidad en devenir dialógico, es lo social y éticamente sustentable. 


\section{Notas}

${ }^{1}$ Cf. UNESCO, 2001, Informe mundial sobre la cultura. Madrid: Mundi-Prensa, cap. 4 y 7.

${ }^{2}$ Cf. M. Castells, 2000, 2001, 2001a y 2001b.

${ }^{3}$ Cf M. Weber, 1988 y A. González, 1994a.

${ }^{4}$ Cf. G. H. Mead, 1962; A. González, 1994a.

${ }^{5}$ Cf. E. Durkheim, 1970; A. González, 1994a.

${ }^{6}$ Cf. T. Parsons, 1949; A. González, 1994a.

${ }^{7}$ Cf. N. Luhmann, 1988; A. González, 1994a.

${ }^{8}$ Cf. I. Wallerstein, 1979; A. González, 1994a.

${ }^{9}$ Cf. J. Habermas, 1981a y 1981b; A. González, 1994a. 
Polis, Revista Latinoamericana, Volumen 14, $N^{\circ}$ 41, 2015

\section{Bibliografía}

Castells, Manuel (2000), La era de la información. La sociedad red. Alianza, Vol. 1, Madrid.

Ídem (2001a), La era de la información. Economía sociedad y cultura: el poder de la identidad. Alianza, Vol. 2, Madrid.

Ídem (32001), La era de la información. Fin del milenio. Alianza, Vol. 3, Madrid.

Ídem (2001b), La Galaxia Internet. Reflexiones sobre Internet, empresa y sociedad. Areté, Barcelona.

Durkheim, E. (1970), La sciencesociale et l' action. PressesUniversitaires de France, París.

González, Antonio (1986), "La idea de mundo en la filosofía de Zubiri", en Miscelanea Comillas, 44, 485-521.

Ídem (1987), "El Hombre en el Horizonte de la Praxis", en ECA, EneroFebrero, 57-87.

Ídem (1994a), Un solo Mundo: la relevancia de Zubiri para la teoría social (tesis doctoral). Universidad Pontificia Comillas, Madrid.

Ídem (1994b), "Orden mundial y liberación", en ECA, 549, Julio, 629-653.

Ídem (1997a), Estructuras de la praxis: ensayo de una filosofía primera. Trotta, Fundación X. Zubiri, Madrid.

Ídem (1997b), "Fundamentos filosóficos de una civilización de la pobreza", en ECA, 583, Mayo, 417-426.

Habermas, J. (1981a), Theorie des kommunikativenHandelns. Band I. Handlungsrationalität und gesellschaftlicheRationalisierung. SuhrkampVerlag, 31999, Band I, Frankfurt am Main.

Ídem (1981b), Theorie des kommunikativenHandelns. Band II. ZurKritik der funktionalistischenVernunft. SuhrkampVerlag,31999 Band II, Frankfurt am Main.

Husserl, Edmund (1962), Die Krisis der europäisch en Wissenschaften und die transzendentale Phänomenologie. Martinus Nijhoff, Haag. [La crisis de las ciencias europeas y la fenomenología transcendental. Crítica, 1991, Barcelona].

Ídem (1982), La Idea de la fenomenología. Fondo de Cultura Económica, México. 
Luhmann, N. (1988), SozialeSysteme. GrundrisseinerallgemeinenTheorie. Suhrkamp, Frankfurt.

Mead, G. H. (1962), Mind, Self and Society. From the Standpoint of a Social Behaviorist. The University of Chicago Press, Chicago.

Parsons, T. (1949), Essays in Sociological Theory Pure and Appied. The Free Press, Glencoe.

Wallerstein I. (1979), The Capitalist World Economy. University Press, Cambridge.

Weber, Max (1988), Gesammelte Aufsätze Wissenschaftslehre. Taschenbuch Ausgabe, Tubinga.

Recibido: 26.07.2015

Aceptado: 15.08.2015 